\title{
A study of the clinical profile of atrial fibrillation in a tertiary care super-specialty referral centre in Central Nepal
}

\section{MP Gautam, ${ }^{1}$ S Gautam, ${ }^{1}$ S Guru Prasad, ${ }^{2}$ G Subramanyam, ${ }^{3}$ U Ghimire ${ }^{4}$}

${ }^{1}$ DM Cardiology residents, ${ }^{2}$ DM Cardiology, Associate Professor, ${ }^{3}$ DM Cardiology, Professor, Department of Cardiology, College of Medical Sciences-Teaching Hospital (Affiliated to Kathmandu University), ${ }^{4} \mathrm{PhD}$, Consultant, COMAT, Kathmandu, Nepal

\section{ABSTRACT}

\section{Background}

The conventional causes and risk factors for atrial fibrillation (AF) are somewhat arbitrary; overlap exists, multiple aetiologies are often present in one individual, and clinical presentation is non- specific. This study was an attempt to study the clinical and echocardiographic profile of patients with AF in a tertiary care super-specialty hospital of a developing country.

\section{Materials and Methods}

This study was conducted in College of Medical Sciences, Chitwan, Nepal throughout the year 2010. Subjects with AF, diagnosed based on clinical history, medical records and surface ECG, were included in the study. The presentation, types and causes of AF and structural as well as functional abnormalities were assessed.

\section{Results}

A total of 136 consecutive subjects were included in the study. The mean age was 42.40 (20.48) years ranging from 17 to 80 years. Majority of the AF subjects were female (54.41\%). Among symptomatic cases, palpitation was the most common (23.53\%) presentation followed by dyspnea (17.65\%) and stroke or transient ischemic attack (15.44\%). Asymptomatic presentation was also not uncommon (25\%). Persistent AF was the most common form (31.62\%). Rheumatic heart disease was the most common cause $(33.09 \%)$ followed by lone atrial fibrillation (23.52\%), coronary artery disease (16.18\%), hypertension $(8.82 \%)$ and thyrotoxicosis $(7.35 \%)$. Other causes included chronic obstructive airway disease $(5.88 \%)$, diabetes (2.94\%), cardiomyopathy (1.47\%), constrictive pericarditis (1.47\%), myocarditis $(0.74 \%)$ and infective endocarditis $(0.74 \%)$. Nearly $65 \%$ subjects had either structural or functional abnormalities in echocardiographic study; dilated left atrium was the most prevalent abnormality.

\section{Conclusion}

In contrast to the studies reported from developed nations, our subjects with AF were younger and female, the most common cause was RHD and the majority had either structural or functional abnormalities in echocardiographic study.

Key words: Atrial fibrillation; anticoagulation; clinical profile. 
Journal of College of Medical Sciences-Nepal, 2012, Vol-8, No-3

\section{Introducation}

Atrial fibrillation (AF) is the most common sustained cardiac arrhythmia and is characterized by uncoordinated atrial activation with consequent loss of atrial mechanical function. ECG show rapid fibrillatory waves with varying morphology and ventricular rhythm that is irregularly irregular with possibly changing QRS morphology as well. ${ }^{1}$ Clinically, it is recognized by irregularly irregular pulse with varying rates ranging from normal to 200 and pulse deficit of more than 10 beats per minute. An irregular rhythm with no obvious P wave in ECG is the hall mark sign of atrial fibrillation.

Despite its common occurrence in clinical practice, $\mathrm{AF}$ is an underestimated disease. The lifetime risk of developing AF is approximately $25 \%$, and it mainly affects older persons ${ }^{2}$. The overall prevalence of AF in general population is estimated to be $0.4 \%$ to $1 \%$. $^{3}$ The incidence of AF is $0.1 \%$ per year in the population below 40 years and increases to $2 \%$ in those over 80 years. ${ }^{4}$ In developed countries and Western World, its incidence has been found increasing. ${ }^{5,6}$ The incidence and prevalence of atrial fibrillation increase exponentially with age. ${ }^{7}$ The adjusted incidence and prevalence of $\mathrm{AF}$ is roughly double for each advancing decade of life, ${ }^{8,9}$ and, at any given age, men have an approximately $50 \%$ higher incidence of AF than women. ${ }^{8}$ Established risk factors for AF include cardiac conditions, such as systolic and diastolic heart failure, valvular heart disease, and myocardial infarction, and cardiovascular risk factors, such as hypertension, diabetes mellitus, obesity, and cigarette smoking. ${ }^{8,10,11,12}$ Subclinical markers indicating increased AF risk include increased arterial stiffness ${ }^{13}$ and echocardiographic evidence of structural heart disease, such as left atrial enlargement, left ventricular hypertrophy, and left ventricular systolic and diastolic dysfunction. ${ }^{14,15}$ Recently identified novel markers associated with increased risk for AF include inflammatory and neurohumoral biomarkers, ${ }^{16,17}$ obstructive sleep apnoea, ${ }^{18}$ and metabolic syndrome. ${ }^{19}$

Clinically, AF has been classified ${ }^{20,21}$ by American Heart Association / American College of Cardiology/ European Society of Cardiology into first detected episode, recurrent (two or more episode), paroxysmal (terminates within 7 days), persistent (persist for more than 7 days) and permanent (sustained for more than 1 year or has unsuccessful cardio version). Its clinical significance and need on treatment are mainly due to complications that include thromboembolic events including fatal stroke, ${ }^{22}$ heart failure, ${ }^{23}$ and increased morbidity and mortality not explained by cardiovascular co morbidity alone. ${ }^{24}$ The reasons for the increase in prevalence are not fully clear. In Western countries, the main reasons are an aging population and longer survival times with cardiovascular diseases. Although, data are lacking regarding the causes and its profile from developing countries, its prevalence is might have been increased because of increased accessibility to health care facility and getting diagnosed their heart condition. One of the studies had reported rheumatic heart disease as the most common reason of atrial fibrillation in developing countries. ${ }^{25}$ The increasing awareness of AF and heart diseases, leading to more frequent visit to cardiologist, may also play a role. ${ }^{2}$ Its prevalence from Nepal and other developing word largely remains unreported. Hence this study was designed with an objective to establish the etiological profile and clinical presentation of atrial fibrillation patients in Nepal. 
MP Gautam et al. study of the clinical profile of atrial fibrillation

\section{Materials and Methods}

This observational hospital based study was carried out in the Department of Cardiology, College of Medical Sciences, Bharatpur Chitwan, Nepal from January 2010 to December 2010 after taking ethical clearance from the Institutional Review Board. Subjects with AF, diagnosed based on surface ECG, were included in the study. The types and causes of AF and structural as well as functional abnormalities as shown by transthoracic echocardiography were recorded. The patients with first episode, recurrent episode, paroxysmal episode and persistent or permanent atrial fibrillation (having clinical and electrocardiographic evidence of AF) were included in this study. The diagnosis of AF was made on the basis of history, clinical examination, examination of previous ECGs and confirmation with 12 leads ECG and 2-D Echocardiography. Subjects were clinically evaluated to establish a clinical diagnosis using other possible laboratory and radiological investigations. Subjects having normal ECG on presentation but having the history of atrial fibrillation without any 12 lead surface ECG evidence were excluded from the study. If they had at least one 12 lead surface ECG showing atrial fibrillation were included in the study. As the study was a cross-sectional one, the distinction between paroxysmal, persistent and permanent atrial fibrillation was based on clinical history and previous ECG reports. Single episode AF without previous ECG evidence was taken as first detected AF. Recurrent episode $\mathrm{AF}$ and paroxysmal $\mathrm{AF}$ were the subjects with previous clinical history and ECG evidence of AF and at least one ECG with sinus rhythm in between. Recurrent episode AF as a presentation of persistent AF was not possible in our study due to lack of evidence whether the episodes were lasted for more than 7 days or not. They were taken as paroxysmal AF. Subjects were taken as having persistent AF if they had atrial fibrillation lasting for more than 7 days supported either by medical records or by 12 lead surface ECG. Permanent AF was the subjects with sustained AF lasting for more than 1 year despite regular medicine intake evidenced by medical records and history. Data analysis was done using MS Excel 2010. Results were displayed as the number of subjects, percentages or mean with standard deviation in brackets.

\section{Results}

A total of 136 consecutive subjects meeting the inclusion criteria were included in the study. The mean age was 42.40 (20.48) years ranging from 17 to 80 years. Majority of the AF subjects were female (54.41\%). The age distribution of these subjects is shown in the table 1. Majority subjects were in the age group 20-60 years of age (more than 75\%). Nearly one-forth subjects were from the age group 30-39 years. There were 2 subjects below 20 years of age and 3 subjects above 80 years of age.

\section{Table 1: Age distribution}

\begin{tabular}{lcc}
\hline $\begin{array}{l}\text { Age } \\
\text { group }\end{array}$ & $\begin{array}{c}\text { Number of } \\
\text { subjects }(\mathbf{n}=\mathbf{1 3 6})\end{array}$ & $\begin{array}{c}\text { Percen- } \\
\text { tage }\end{array}$ \\
\hline Below 20 years & 2 & 1.47 \\
$20-29$ & 26 & 19.12 \\
$30-39$ & 33 & 24.26 \\
$40-49$ & 23 & 16.91 \\
$50-59$ & 21 & 15.44 \\
$60-69$ & 19 & 13.97 \\
$70-79$ & 9 & 6.62 \\
Above 80 years & 3 & 2.21 \\
\hline
\end{tabular}


Journal of College of Medical Sciences-Nepal, 2012, Vol-8, No-3

Palpitation was the most common (23.53\%) presenting complaints. One-forth subjects did not have any complaints. Dyspnea and stroke or transient ischemic attacks (TIA) were the less common presentation (17.65\% and $15.44 \%$ respectively). Syncope was presenting complaint in $8.82 \%$ subjects. Acute pulmonary edema and chest pain were the least common presentations in our subjects (5.15\% and $4.41 \%$ respectively).

Table 2. Presenting complaints in AF subjects

\begin{tabular}{lcc}
\hline Complaints & $\begin{array}{c}\text { Number of } \\
\text { subjects }(\mathbf{n}=\mathbf{1 3 6})\end{array}$ & $\begin{array}{c}\text { Percen- } \\
\text { tage }\end{array}$ \\
\hline Palpitation & 32 & 23.53 \\
Dyspnea & 24 & 17.65 \\
Stroke or TIA & 21 & 15.44 \\
Syncope & 12 & 8.82 \\
Acute pulmonary edema & 7 & 5.15 \\
Chest pain & 6 & 4.41 \\
Asymptomatic & 34 & 25.00 \\
\hline
\end{tabular}

Regarding the type of atrial fibrillation, persistent atrial fibrillation was the most common (31.62\%) in our study subjects followed by permanent atrial fibrillation (27.21\%). Less than one-forth subjects were detected first time. Less than one-fifth (17.62\%) subjects were evaluated as recurrent episode or paroxysmal AF.

Table 3: Types of atrial fibrillation

\begin{tabular}{lcc}
\hline $\begin{array}{l}\text { Types of atrial } \\
\text { fibrillation }\end{array}$ & $\begin{array}{c}\text { Number of } \\
\text { subjects }(\mathbf{n}=\mathbf{1 3 6})\end{array}$ & $\begin{array}{c}\text { Percen- } \\
\text { tage }\end{array}$ \\
\hline $\begin{array}{l}\text { First detected } \\
\text { episode AF }\end{array}$ & 32 & 23.53 \\
$\begin{array}{l}\text { Recurrent episode } \\
\text { AF and Paroxysmal AF }\end{array}$ & 24 & 17.65 \\
Persistent AF & 43 & 31.62 \\
Permanent AF & 37 & 27.21 \\
\hline
\end{tabular}

Among the causes of atrial fibrillation, rheumatic heart disease was the most common condition and presented in one-third subjects. RHD was followed by idiopathic cause as a reason of atrial fibrillation (21.32\%) and were diagnosed as lone atrial fibrillation. Coronary artery disease was the third common (16.18\%) cause in our subjects. Hypertension, thyrotoxicosis and COPD were in the $4^{\text {th }}, 5^{\text {th }}$, and $6^{\text {th }}$ position with $8.82 \%$, $7.35 \%$ and $5.88 \%$ respectively. Nearly $3 \%$ subjects had diabetes as a sole cause of atrial fibrillation. Cardiomyopathy and constrictive pericarditis were the less common condition as a cause of AF ( 2 subjects with each condition). Myocarditis and infective endocarditis were the least common conditions (one with each condition).

Table 4: Causes of atrial fibrillation

\begin{tabular}{lcc}
\hline Causes & \multicolumn{1}{c}{$\begin{array}{c}\text { Number of } \\
\text { subjects }(\mathbf{n}=\mathbf{1 3 6})\end{array}$} & $\begin{array}{c}\text { Percen- } \\
\text { tage }\end{array}$ \\
\hline Rhematic heart disease & 45 & 33.09 \\
Coronary artery disease & 22 & 16.18 \\
Hypertension & 12 & 8.82 \\
Thyrotoxicosis & 10 & 7.35 \\
COPD & 8 & 5.88 \\
Diabetes & 4 & 2.94 \\
Cardiomyopathy & 2 & 1.47 \\
Constrictive pericarditis & 2 & 1.47 \\
Infective endocarditis & 1 & 0.74 \\
Myocarditis & 1 & 0.74 \\
Unknown (loneAF) & 29 & 21.32 \\
\hline
\end{tabular}

Nearly $65 \%$ subjects had either structural or functional abnormalities in echocardiographic study and remaining patients had normal echo study. Regarding left atrium size, majority subjects had dilated left atrium size (table 5). 
MP Gautam et al. study of the clinical profile of atrial fibrillation

Table 5: Left atrium size in atrial fibrillation subjects

\begin{tabular}{lcc}
\hline LA Size & $\begin{array}{c}\text { Number of } \\
\text { subjects }(\mathbf{n}=\mathbf{1 3 6})\end{array}$ & $\begin{array}{c}\text { Percen- } \\
\text { tage }\end{array}$ \\
\hline Less than $4 \mathrm{~cm}$ & 58 & 42.65 \\
4 to $5 \mathrm{~cm}$ & 47 & 34.56 \\
More than $5 \mathrm{~cm}$ & 31 & 22.79 \\
\hline
\end{tabular}

\section{Discussion}

This was the first of its kind study from Nepal and it had shown a definite unique pattern of atrial fibrillation profile in our population in comparison to western countries. Majority of the subjects were from the age group 20-59 years; more than $75 \%$ subjects fall in this age group. The age distribution of patients in this study with mean age of $42.40 \pm 20.48$ years was more or less consistent with most Indian studies but differed significantly from western studies due to low prevalence of rheumatic heart disease in their population. ${ }^{7,1,2} \mathrm{~A}$ higher proportion (54.41\%) of the patients were females as compared to males (45.59\%). This was in contrast to the other studies ${ }^{8,27,28}$ where higher proportion of male subjects was reported.

The most common presentation in our subjects was palpitation. Nearly one in four subjects had palpitation in our study. This is comparable to similar findings in other studies. ${ }^{27}$ However, some studies had reported dyspnea as the most (74\%) common presentations followed by palpitation in $57 \% .{ }^{29}$ In their studies there was significant overlapping of the presenting complaints and higher rates of all complaints were reported. In our study we had only taken the first complaints for study purpose. Another unique feature in our study is the rates of asymptomatic presentations; one in four subjects was asymptomatic and AF was the incidental finding. This was in contrast to other studies reported from India; ${ }^{27,30}$ the rates of asymptomatic presentation in their studies were $2 \%$ and $14 \%$ respectively. The spectrum of presenting complaints was more or less similar to our studies. In our study, other presenting complaints were dyspnea, stroke and transient ischemic attack, acute pulmonary edema and chest pain. These observations are similar to a previous reported study by Fuster et $\mathrm{a}^{20}$ except higher rates of asymptomatic presentation in our study.

In our study most of the subjects had either persistent (31.62\%) or permanent (27.21\%) atrial fibrillation. Only 23.53\% subjects had first episode atrial fibrillation and $17.65 \%$ subjects had paroxysmal or recurrent episode AF.

Among the causes of AF, rheumatic heart disease was the most prevalent condition, which was present in every third subject. This was followed by idiopathic group as a cause for AF. Coronary artery disease (16.18\%), hypertension (8.82\%) were the next common conditions associated with atrial fibrillation. Thyrotoxicosis (7.53\%), chronic obstructive airway disease (5.88\%) and diabetes (2.94\%) were the important causes among non-structural heart disease. Constrictive pericarditis, cardiomyopathy, myocarditis, infective endocarditis were the rare conditions associated with AF. Similar observation was also reported recently from India. Nanda et al ${ }^{27}$ have found structural heart disease in $86.36 \%$ of cases and nonstructural heart disease in $10.6 \%$ of cases. Among the structural heart disease, valvular heart disease was seen in $51.51 \%$ cases as a cause of AF. Thyrotoxicosis (4.54\%) and chronic obstructive airway disease 
Journal of College of Medical Sciences-Nepal, 2012, Vol-8, No-3

(6.06\%) were most important causes among non structural heart disease in their study. Kumar and Soodan ${ }^{30}$ had also reported similar scenario in their study. In both studies, the rates of idiopathic causes as a reason of AF was significantly lower than in our study.

In our study, only 65\% subjects had abnormal echocardiographic findings. Most common abnormality recorded was dilated left atrium. Majority of the study subjects (57.35\%) had dilated left atrium ( $>4 \mathrm{~cm}$ ). Similar higher rates of structural abnormalities including dilated left atrium were also reported by Kumar and Soodan ${ }^{30}$ and Nand et al. ${ }^{27}$ In a study by Nand et al, ${ }^{27} 62.1 \%$ had their left atrial size more than $3.5 \mathrm{~cm}$ and valvular heart disease; particularly mitral stenosis (47\%) and dilated cardiomyopathy (90.09\%) were the main causes of enlarged left atrium. Kumar and Soodan ${ }^{30}$ also had reported dilated left atrium in $68 \%$ subjects. These findings are consistent with those reported by ALFA study. ${ }^{31}$

\section{Limitations}

Our study is not devoid of limitations. First of all, it is a hospital based study and the overall findings of our study might not reflect the real scenario of atrial fibrillation cases in general population. In general population, many subtle form of AF without any symptoms might remain undetected lifelong. Similarly, the cross-sectional nature of the study might cause major fallacy in the atrial fibrillation classification as some of the AF cases might have been classified otherwise if observed for longer duration as in prospective studies. Moreover more detail and in depth evaluation of these subjects with the help of more sophisticated advanced medical techniques and genetic studies might establish different condition as the cause of AF in some cases. Despite all these inherent and unavoidable limitations this study had given a reasonable and elaborative scenario of atrial fibrillation in our setup and forms the basement for further investigations.

\section{Conclusion}

This study has established a firm basement in atrial fibrillation research in our scenario. It has given basic clinical profile of atrial fibrillation. In comparison to western studies, our AF cases are younger with female predominance. Palpitation, dyspnea, stroke or transient ischemic attack and syncope are the common presentation. Large group of subjects may still be asymptomatic as well. Persistent AF and permanent AF are the important form of atrial fibrillation. RHD, coronary artery disease, hypertension, thyrotoxicosis, COPD, diabetes are the potential risk factors for the occurrence of atrial fibrillation. Majority of the subjects had structural abnormalities in echocardiographic study and left atrial enlargement is a frequent occurrence.

\section{Acknowledgement}

Mid-term analysis of this study was presented in the First International Conference of Cardiac Society of Nepal held on 11 - 12 November 2010 in Hyatt Regency, Kathmandu, Nepal and paper had won first prize. I would like to acknowledge Professor Rabindra Bhattacharya, Head, Department of Cardiology for the constructive insights while preparing this manuscript.

\section{References}

1. Prystowsky EN, Padanilam BJ, Waldo AL. Hurst's: The Heart. Eds. Valentin F et al. McGraw Hill, 13th Edition 2011;I: 963-81. 
MP Gautam et al. study of the clinical profile of atrial fibrillation.

2. Lloyd-Jones DM, Wang TJ, Leip EP, et al. Lifetime risk for development of atrial fibrillation: the Framingham Heart Study. Circulation. 2004;110: 1042-6.

3. Go AS, Hylek EM , Phillips KA. et al. Prevalence of diagnosed atrial fibrillation in adults. JAMA 2001;285:2370-5.

4. Wolf PA, Abbott RD, Kannel WB. Atrial fibrillation: A major contributor to stroke in the elderly. The Framingham study. Arch Intern Med 1987;147:1561-4.

5. MiyasakaY, Barnes ME, BJ Gersh et al. Secular trends in incidence of atrial fibrillation in Olmsted County, Minnesota, 1980 to 2000, and implications on the projections for future prevalence. Circulation 2006;114: 119-25.

6. Stefansdottir H, Aspelund T, GudnasonV. et al. Trends in the incidence and prevalence of atrial fibrillation in Iceland and future projections. Europace 2011;13: 1110-7.

7. Falk RH. Atrial Fibrillation. New Eng. J. Med.2001;344:1067-77.

8. Benjamin EJ, Levy D, Vaziri SM et al. Independent risk factors for atrial fibrillation in a population-based cohort: the Framingham Heart Study. JAMA. 1994; 271: 840-4.

9. AS Go, EM Hylek, KA Phillips et al. Prevalence of diagnosed atrial fibrillation in adults: national implications for rhythm management and stroke prevention: the Anticoagulation and Risk Factors in Atrial Fibrillation (ATRIA) Study. JAMA. 2001;285: 2370-5.

10. Wang TJ , Parise H, Levy D et al. Obesity and the risk of new-onset atrial fibrillation. JAMA 2004;292:2471-7.

11. Dublin S, French B, Glazer NL et al. Risk of new-onset atrial fibrillation in relation to body mass index. Arch Intern Med. 2006; 166: 2322-8.
12. Thomas MC, Dublin S, Kaplan RC et al. Blood pressure control and risk of incident atrial fibrillation. Am J Hypertens. 2008; 21: 1111-6.

13. Mitchell GF, Vasan RS, Keyes MJ et al. Pulse pressure and risk of new-onsetatrial fibrillation. JAMA 2007; 297: 709-15.

14. Vaziri SM, Larson MG, Benjamin EJ et al. Echocardiographic predictors of nonrheumatic atrial fibrillation: the Framingham Heart Study. Circulation 1994; 89:724-30.

15. Tsang TS, Gersh BJ, Appleton CP et al. Montgomery SC, Seward JB. Left ventricular diastolic dysfunction as a predictor of the first diagnosed non-valvular atrial fibrillation in 840 elderly men and women. J Am Coll Cardiol. 2002; 40: 1636-44.

16. Aviles RJ, Martin DO, Apperson-Hansen C et al. Inflammation as a risk factor for atrial fibrillation. Circulation 2003; 108:3006-10.

17. Wang TJ, Larson MG, Levy D et al. Plasma natriuretic peptide levels and the risk of cardiovascular events and death. N Engl J Med. 2004; 350: 655-63.

18. Gami AS, Hodge DO, Herges RM et al. Obstructive sleep apnea, obesity, and the risk of incident atrial fibrillation. J Am Coll Cardiol. 2007; 49:565-71.

19. Watanabe H, Tanabe N, Watanabe $\mathrm{T}$ et al. Metabolic syndrome and risk of development of atrial fibrillation: the Niigata preventive medicine study. Circulation. 2008; 117: 1255-60.

20. Fuster V, Ryden LE, Asinger RW et al. ACC/AHA/ESC guidelines for the management of patient with atrial fibrillation (Committee to develop guidelines for the management of patients with AF). Circulation 2001; 104: 2118-50. 
Journal of College of Medical Sciences-Nepal, 2012, Vol-8, No-3

21. Levy S. Classification system of Atrial Fibrillation. Cur. Opin. Cardiol. 2000;15:54-7.

22. Currie CJ, Jones M, Goodfellow J et al. Evaluation of survival and ischaemic and thromboembolic event rates in patients with nonvalvar atrial fibrillation in the general population when treated and untreated with warfarin. Heart 2006; 92: 196-200.

23. Wang TJ, Larson MG, Levy D et al. Temporal relations of atrial fibrillation and congestive heart failure and their joint influence on mortality: the Framingham Heart Study. Circulation 2003; 107:2920-5.

24. Benjamin EJ, Wolf PA, Agostino RB D et al. Impact of atrial fibrillation on the risk of death: the Framingham Heart Study. Circulation 1998; 98: 946-52.

25. Ray IB. Acute management of atrial fibrillation: The commonest arrhythmia in clinical practice. JIMA 2004; 102(4):209-10.

26. Markides V, Schilling RJ. Atrial fibrillation; classification, pathophysiology, mechanism and drug treatment. Heart 2003;89:939-43.
27. Nanda V, Gupta AK, Mahmood SE et al. Etiological profile and clinical presentation of patients with atrial fibrillation from a rural area of Bihar. National Journal of Medical Research 2012; 2(2):124-7.

28. Furberg CD, Psaty BM, Manolio TA et al. Prevalence of atrial fibrillation in elderly subject (the cardiovascular health study) Am. J. Cardiol. 1994; 74(3) : 236-41.

29. Kannel WB, Namara MC, Abott RD. Coronary heart disease and atrial fibrillation, The Framingham study. Am heart J. 1993;106: 389-96.

30. Kumar T, Soodan SS. Clinical and echocardiographic profile of atrial fibrillation. JK Science 2011;13(2):73-5.

31. Levy S, Maarek M, Coumel P et al. Characterization of different subsets of atrial fibrillation in general practice in France: the ALFA study. The College of French Cardiologists. Circulation 1999; 99: 3028-35. 